\title{
Is nitrate a driver for pigments of phytoplankton (a case study from a small shallow European lake)?
}

\author{
Alexandra L. Rizhinashvili ${ }^{1, *}$ and Olga B. Maksimova ${ }^{2}$ \\ ${ }^{1}$ St. Petersburg Branch of S.I. Vavilov Institute for the History of Science and Technology of the Russian Academy of Sciences, \\ Universitetskaya naberezhnaya, 5, 199034 St. Petersburg, Russia \\ ${ }^{2}$ Berg State Researh Institute on Lake and River Fisheries, Makarova naberezhnaya, 26, 199053 St. Petersburg, Russia
}

Received: 9 February 2018; Accepted: 5 November 2018

\begin{abstract}
The traditional view of biogenic limitation in freshwater ecosystems considers phosphorus as the primary limiting element, but this concept has recently been challenged. There are a number of studies that suggest that photosynthetic indices may depend on the levels of nitrogen (especially, nitrate-nitrogen). To test the hypothesis about the possibility of nitrogen limitation in the lake ecosystem, the present study analysed the water in the littoral zone of a shallow model lake for the relationship between the content of phytoplankton pigments (chlorophyll $a$ and carotenoids) and nitrate. The nitrate-nitrogen was selected because it is the most chemically stable nitrogen species. The study was conducted in a small lake with a pronounced autochthonous regime (as indicated by its small drainage ratio) during a vegetation season with contrasting hydrological conditions. The relationship with the nitrate concentration was not confirmed for chlorophyll $a$, but the levels of nitrate anion and carotenoids were shown to be related. Chlorophyll $a$, which is regarded as a metabolically active component of phytoplankton cells, shows a close correlation with air temperature. The corresponding prognostic regression models were created. The data on nominal availability of nitrate-nitrogen for primary production show possible nitrogen limitation on some of the observation dates. If the production potential represented by certain levels of nitrate is not realised by phytoplankton, it can be used by filamentous algae. The results of the study provide first steps toward prediction of one of the indicators of phytoplankton growth, the content of two main types of pigment (chlorophyll $a$ and carotenoids).
\end{abstract}

Keywords: lake ecosystem / small shallow lake / nitrate / chlorophyll $a$ / carotenoids

\section{Introduction}

The problem of an increase in the trophic status of water bodies has been traditionally linked to the input of phosphorus substances. Phosphorus is very often viewed as a limiting element for primary production both in fresh and sea waters (Lean, 1973; Nesvetova, 2002; Håkanson and Boulion, 2003; Datsenko, 2007; Hennemann and Petrucio, 2016). This can be easily explained by low phosphorus mobility in the biosphere and low solubility of phosphorus compounds. By contrast, the nitrogen loss in water ecosystems is thought to be always compensated by nitrogen fixation (Moss et al., 2013). However, over the last decade, a growing number of publications have shown evidence of dependence of photosynthetic indices and phytoplankton abundance on the nitrogen content in water (Vanni et al.,

\footnotetext{
*Corresponding author: railway-ecology@yandex.ru
}

2010; Moss et al., 2013; Mineeva et al., 2016; Williams et al., 2016). The type of limitation (either by phosphorus or by nitrogen) was shown to be related to zonal characteristics of water bodies (Gashkina, 2011), the type of land use in their catchments (Moss et al., 2013; Hayes et al., 2015), the climatic and seasonal hydrological conditions and the type of water mixing in the lake (Hayes et al., 2015; Dolman et al., 2016). Special importance was attached to the relationship of the nitrate anion concentration with precipitation level and water exchange in the water bodies (Moss et al., 2013). It was explained by high mobility of this ion and its fast leaching from the catchment. There were also attempts to create regression models predicting the chlorophyll content based on the nitrate concentration and water discharge (Luzar, 2009). Nitrogen limitation can result from the competition between phyto- and bacterioplankton under conditions of increased carbohydrate supply in the environment (Freese et al., 2007). Nevertheless, there is still no single theoretical model explaining which physico-chemical and biotic conditions 
account for the emergence and maintenance of nitrogen limitation of the production in the lakes.

Consequently, the study of interrelations between the production characteristics of the lakes and the nitrogen level in the water is essential to further the theory of eutrophication of water bodies and to develop a framework for its monitoring and prediction. This analysis must also take into account the assessment of nitrogen availability (i.e. limitation) for the primary production of phytoplankton. Special attention should be given to the small, shallow lakes that have the highest biological activity due to a large area of the littoral zone (a well-warmed near-shore zone where sunlight reaches all the way to the lake bottom). We think that the level of organic nitrogen compounds cannot be used as a measure of nitrogen availability, because they themselves arise as the result of primary production. The $\mathrm{NH}_{4}{ }^{+}, \mathrm{NO}_{3}{ }^{-}$and $\mathrm{NO}_{2}{ }^{-}$ ions often exported from the catchment or emerging in the internal nitrogen cycle of the water body are directly utilised by phytoplankton for production (Glibert et al., 2016). Of these ions, $\mathrm{NO}_{2}{ }^{-}$is normally observed in water in negligibly small concentrations, while the ammonium and nitrate ions are present in appreciable concentrations, with $\mathrm{NO}_{3}{ }^{-}$being the most stable ion in oxidative conditions under good aeration of water and due to the nitrification prevailing in such environment (Quiros, 2003; Lozovik and Borodulina, 2009). Thus, the nitrate is often dominating nitrogen species in the water bodies in many regions (Hayes et al., 2015), especially in the mesotrophic lakes with aerobic conditions (Quiros, 2003). In general, in any lake (any trophic status worldwide), content of the nitrate is higher at many times (from 3 to 10) than concentration of the ammonium (Quiros, 2003). For example, in the waters of northwestern Russia, according to Trifonova et al. (2002), throughout the vegetation season concentration of the ammonium doesn't exceed $0.04 \mathrm{mg} \cdot \mathrm{L}^{-1}$ at all. The nitrate levels can therefore be effectively used for the assessment of the productive potential of the water body. Moreover, we have some successful experience of using $\mathrm{NO}_{3}{ }^{-}$concentration for evaluation of the productive ability of some European lakes with different trophic status (Rizhinashvili and Maksimova, 2018). The content of $\mathrm{NH}_{4}{ }^{+}$ was so low that it did not change estimation by $\mathrm{NO}_{3}{ }^{-}$. In addition, basing on our previous studies, the balances of the oxygen and the nitrate in littoral waters of the mesotrophic lake are concordant (Rizhinashvili, 2017) and in good agreement with the primary production (Rizhinashvili and Maksimova, 2018).

The aim of this study was to test the hypothesis that the $\mathrm{NO}_{3}{ }^{-}$anion is associated with the concentration of chlorophyll $a$ and carotenoids, the major pigments of phytoplankton. The pigment concentration was selected as a variable reflecting the productive ability of the ecosystem because of its highly conservative nature. The pigment concentration is regarded as a better measure of the lake's trophic status than the rate of primary production (Likens, 1975). The study was based on observations during one vegetative season with contrasting hydrological conditions. The water body selected as a model for this study was a shallow mesotrophic lake with a marked autochthonous regime (small drainage ratio, slow water exchange, the lack of tributaries and local contaminants), i.e. the lake that has a lowest dependence on the conditions in the catchment.

\section{Material and methods}

\subsection{Brief description of the study (model) lake}

Lake Hupujarvi is situated $7 \mathrm{~km}$ to the northeast of the railroad station Vaskelovo (Vsevolozhsky District of the Leningrad Region) on the Karelian Isthmus, one of the lacustrine regions of northwestern European Russia. The lake is characterised by a small drainage ratio (7.71; the drainage area is $2.16 \mathrm{~km}^{2}$ ), which explains its autochthonous regime and slow water exchange (our longterm observations show that over the period from May to September, the water exchange coefficient ranges from 0.00 to 0.13 per year). The water surface area is $0.28 \mathrm{~km}^{2}$; the littoral zone accounts for $21 \%$ of this area. The average depth is $2.14 \mathrm{~m}$; the maximum depth is $3.8 \mathrm{~m}$. Sixty-five percent of the catchment is occupied by garden plots, and the rest is covered by forest. The lake is open; it is drained by an unnamed brook. The lake is not affected by any source of pollution, except for the surface runoff from the territory of the catchment. The detailed morphometric and hydrochemical characteristics of the lake and its bathymetric map were given elsewhere (Rizhinashvili, 2017). Here, we especially emphasise constant extremely low (at the level of analytical traces) content of the phosphate $\left(<0.01 \mathrm{mg} \cdot \mathrm{L}^{-1}\right)$ in the lake. Long-term measurements of primary production in this lake show that in terms of the trophic status it can be classified as mesotrophic with eutrophic tendencies (Rizhinashvili, 2017). Regarding the composition of phytoplankton, the small and mesotrophic unpolluted lakes of the Karelian Isthmus and adjacent areas (e.g. Finland) have diatoms as the main group prevailing by its biomass (from $50 \%$ and up to $90 \%$ ) during all vegetation season (Lepisto, 1999; Trifonova et al., 2002). Thus, we can consider that such composition is also inherent for Lake Hupujarvi.

\subsection{Sampling technique and methods of measurement}

Production and hydrochemical variables were measured from water samples collected manually during the vegetation season (May-September 2016) from the littoral zone (nearshore area of the lake delimited by the $1 \mathrm{~m}$ isobath (Rizhinashvili, 2017)) in the middle portion of the water column. The samples were collected twice a month from two sufficiently distant sites following the most commonly used procedure of lake study (Howden and Burt, 2009; Hayes et al., 2015). The sites were selected based on the following criteria: the sampling area was free of macrophyte growth (including vegetation with floating leaves), accumulations of dead plants, and other debris on the lake bottom; the corresponding stretch of the shore was not waterlogged; the sediment consisted of sand, with no sign of silting. These criteria allowed us to avoid the confounding effects from the local processes. The littoral zone is technically more amenable to direct observation and allows a "scale-up" of the production processes, because the rates of these processes are the highest in this zone of the lake. The shallow depths and the lack of thermal stratification can make these samples representative of the lake as a whole, although this assumption needs additional validation in further studies. 
The samples were analysed for the concentration of chlorophyll $a$, carotenoids and nitrate anion. The phytoplankton pigments were measured in the acetone extract using standard spectrophotometric techniques (chlorophyll $a$ following the UNESCO method (Report, 1964); carotenoids following Parsons and Strickland, 1963). The nitrate levels were determined using an ion-selective electrode with an ionmeter pre-calibrated in a series of reference solutions of $\mathrm{KNO}_{3}$. The method of measuring $\mathrm{NO}_{3}{ }^{-}$for limnological and production studies using an ion-selective electrode was successfully used in a previous study (Rizhinashvili, 2017). Daily primary production (PP) was measured separately at the sampling sites using the standard technique of "dark and light bottles". These results were used to calculate daily assimilation numbers (DAN) of phytoplankton (PP divided by the chlorophyll $a$ content).

Since precipitation is one of the primary input sources of substances in the lakes with an autochthonous regime, we also measured nitrate levels in the rainwater collected during all rains that occurred throughout the studied vegetation season (water was analysed for each separate episode of rainfall). As with lake water, the analysis was performed using an ionselective electrode.

The information on water exchange and water level in the lake together with major meteorological factors is necessary to characterise hydrological conditions. The analysis of hydrological characteristics of the lake was performed by periodic measurement of water levels and discharge rates in the outflowing brook using standard hydrological methods (Doganovsky, 2012). The coefficient of external water exchange was calculated from water discharge rates and the volume of water in the lake.

Meteorological data (we studied the most important variables, air temperature and total precipitation) for the 2016 season on the Karelian Isthmus were provided by the Russian State Hydrological Institute.

\subsection{Statistical analysis of data}

The analysis of the data was conducted in two phases.

A preliminary analysis of variation and relationships between hydrological, meteorological and production variables and nitrate levels was performed using the simplest methods of visualisation and two-dimensional statistics (Pearson's correlation coefficient $r$ ). The PP and DAN values were used only during this phase of analysis. In the further analysis, only the pigment concentration was used as a production variable because of a highly conservative nature of this parameter.

During the second phase, the relationships between variables were analysed by factor analysis (principle component analysis, PCA) and forward stepwise algorithm of multiple regression. In addition, the correlation matrix (composed of individual paired Pearson's correlation coefficients) calculated during the first phase was visualised by plotting it on graphs. The graphs were plotted based on absolute values of correlation coefficients and their confidence levels to illustrate separate groups of strongly intercorrelated variables (correlation strength of 0.60 or more). Thus, graphs were built only for closely correlated variables. PCA is also able to identify groups of associated variables. However, unlike the paired data analysis, the component analysis allows for a meaningful interpretation of a set of variables that have the highest loading on the leading principal components. We constructed a diagram of variables in the space of the first three components with eigenvalues of more than 1. Stepwise regression algorithm estimates a relative predictive value of every variable included in a regression model to predict the pigment levels. We first built regression model for the response of the concentration of the principal photosynthetic pigment (chlorophyll $a$; dependent variable) to the remaining variables (nitrate concentration, water level and water exchange coefficient, air temperature, total precipitation; collectively termed predictors in the following text; independent variables) and then constructed regression model for the response of carotenoids (dependent variable) to the same predictors.

All statistical analysis and visualisation were conducted without any data transformations using Statistica 7.0 modules (StatSoft Inc., 2004): Basic Statistics/Tables; 2D GraphsScatterplots, Line plots (Variables); Factor Analysis; General Regression Models-Multiple Regression. Correlation graphs were plotted manually.

\subsection{Stoichiometric analysis of nitrate availability for production}

In addition to the statistical analysis, we performed a stoichiometric analysis of the nominal nitrogen availability for the primary production averaged over the vegetation season. This analysis provides an assessment of the extent to which the observed nitrate concentration in water (assuming that the nitrate reserves and only they were completely depleted by producers) could account for the measured rate of primary production at any given period of observation. To this end, the nitrate concentrations were converted to the oxygen concentrations using the Redfield ratio (Johnson, 2010; Rizhinashvili, 2017), which is 8.625 for the molar ratio of oxygen and nitrate concentrations. We should emphasise that this is calculation of some "potential" production which can be theoretically reached under favourable conditions.

The calculated value of "nitrate" production $\mathrm{PP}_{\mathrm{NO} 3}$ was compared with the measured value of primary production. The nitrate concentrations were averaged separately for the first and second halves of the season, because the nitrate content during these periods differs by an order of magnitude, and averaging over the whole season is meaningless.

\section{Results}

The results of the study were divided into three groups, each described in its own section. The first group of data provides the information on the meteorological and hydrological conditions during the vegetation season under study. The second group presents an overview of the studied production variables and the $\mathrm{NO}_{3}{ }^{-}$ion content (in lake water and precipitation) in terms of variability of these parameters and the assessment of the trophic status of the water body. The third group of the results presents an analysis of the system of relationships between all variables, with the aim to address the 

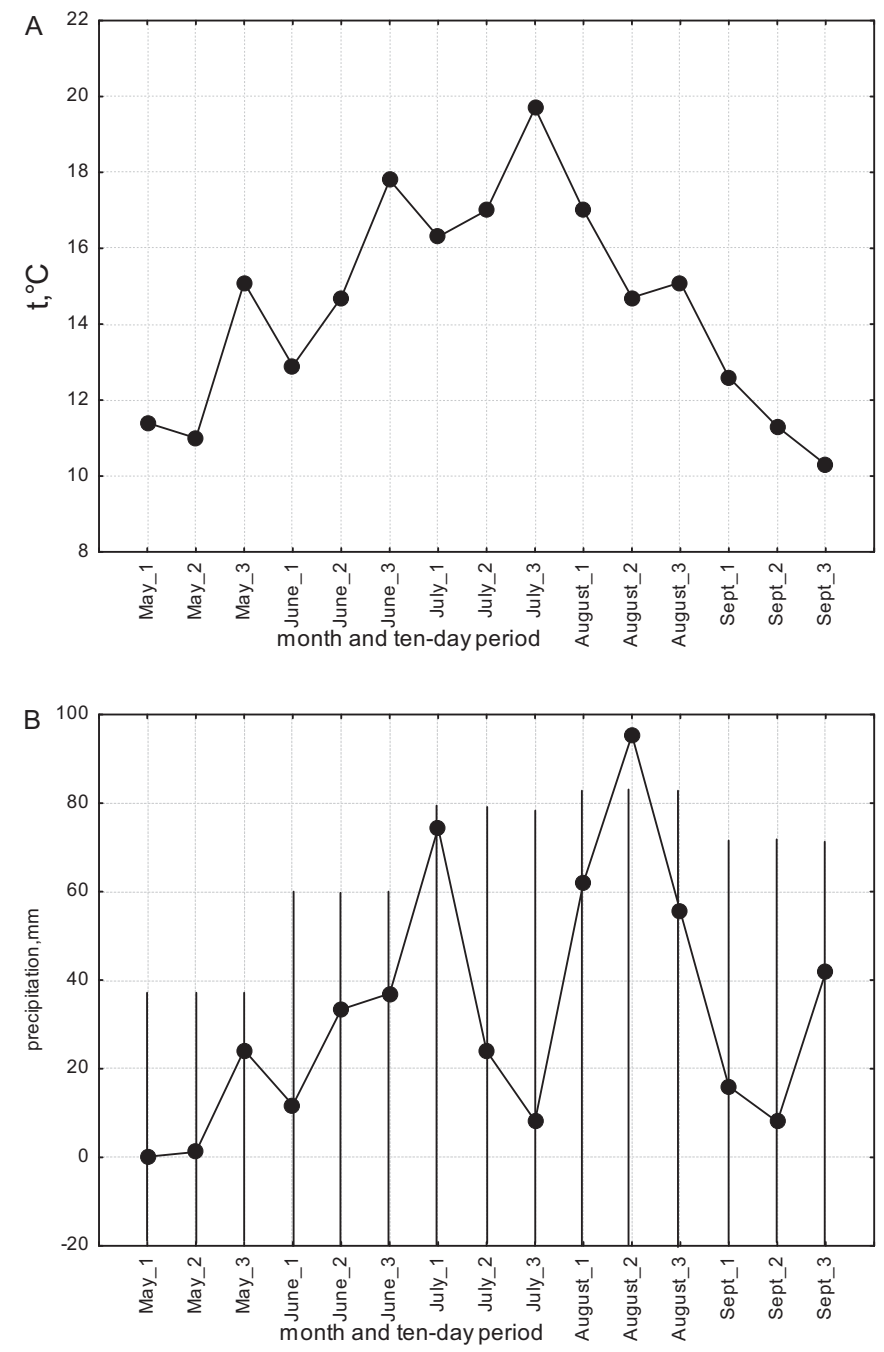

Fig. 1. Air temperature (A) and total precipitation (B) during the 2016 vegetation season (May-September) on the Karelian Isthmus by 10 -day periods (shown as numbers; September is abbreviated to Sept). Vertical lines indicate monthly precipitation norms (average over the years) from the Northwest Administration on Hydrometeorology and Environmental Monitoring (available at: http://www. meteo.nw.ru/articles/index.php?id=2).

possibility of predicting the pigment content based on nitrate levels in the water.

\subsection{Meteorological conditions during the season and variation in water level and water discharge}

During the vegetation season, there was a noticeable increase in air temperature until the end of July (Fig. 1A), when this meteorological parameter reached its maximum. After the maximum, temperature showed a steady decline until the end of the season.

The distribution of rainfall (Fig. 1B) had two distinct maximums, during the first 10-day period of July and during the second 10-day period of August (the highest of the two). The period of the lowest precipitation spanned the second and
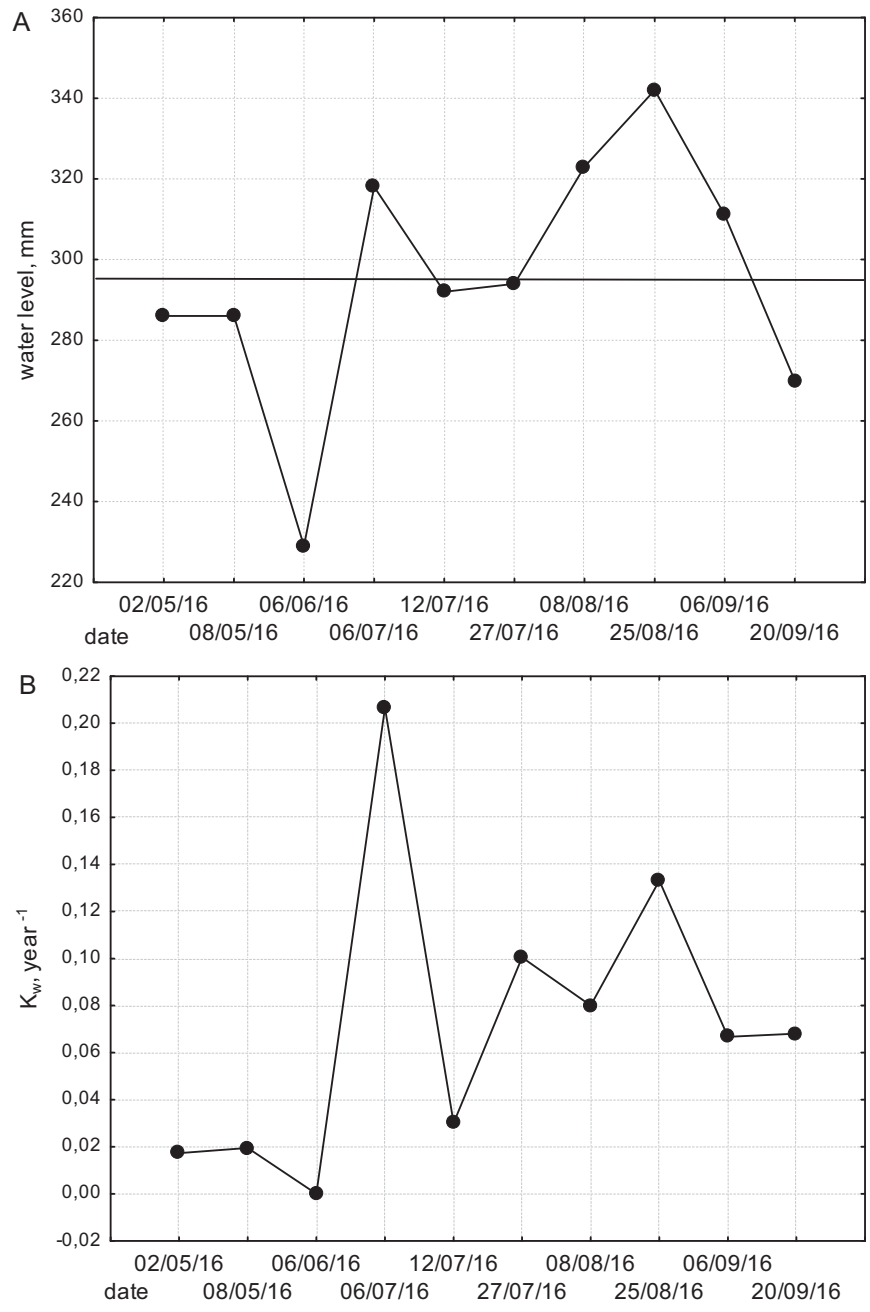

Fig. 2. Water level (A) and water exchange coefficients $\left(K_{\mathrm{w}}\right)(\mathrm{B})$ for Lake Hupujarvi observed during the vegetation season of 2016. The horizontal line indicates the average seasonal water level.

third decades of July. In general, the vegetation season of 2016 was very wet for the Karelian Isthmus.

The stabilisation of the water level with respect to the mean seasonal value occurred in mid-July (i.e. approximately in the middle of the vegetation season) (Fig. 2A). Before that, this parameter was highly unstable, but the water level was generally below average. Following the stabilisation in August, the water level became higher than average. The maximum level occurred by the end of August, followed by the decline over the period of 1 month.

The distribution of the coefficient of external water exchange $\left(K_{\mathrm{W}}\right)$ was much less uniform (Fig. 2B). The minimum water discharge (as low as 0 ) was observed at the very beginning of the vegetation season (before the beginning of June). A rapid rise in water discharge occurred at the beginning of July, before the level stabilisation. In July, the intensity of water exchange fell seven times over the span of several days and approached the minimum value. From the end of July, the lake entered a pronounced leaching regime, because the coefficients of external water exchange were sufficiently high. 
Table 1. Pigments content and photosynthetic activity of phytoplankton in the littoral of Lake Hupujarvi for the period May-September 2016.

\begin{tabular}{lllll}
\hline Index & $a$ & $k$ & $k / a$ & $\begin{array}{l}\mathrm{PP} \\
\mathrm{mgO}_{2} \cdot \mathrm{L}^{-1} \\
\mathrm{per} \text { day }\end{array}$ \\
& $\mu \mathrm{g} \cdot \mathrm{L}^{-1}$ & $\mu \mathrm{g} \cdot \mathrm{L}^{-1}$ & & $\begin{array}{l}\mathrm{DAN} \\
\mathrm{mgC} \cdot \mathrm{mg} a^{-1}\end{array}$ \\
\hline $\begin{array}{l}\text { Mean } \pm \text { standard deviation (whole season) } \\
\text { Variation limits }\end{array}$ & $\begin{array}{l}6.22 \pm 2.211 \\
4.00-9.88\end{array}$ & $\begin{array}{l}6.16 \pm 2.139 \\
3.93-9.54\end{array}$ & $\begin{array}{l}1.01 \pm 0.199 \\
0.81-1.29\end{array}$ & $\begin{array}{l}0.66 \pm 0.449 \\
0.17-1.39\end{array}$ \\
\hline
\end{tabular}

Abbreviations: $a$ : chlorophyll $a$; $k$ : carotenoids; PP: primary production; DAN: daily assimilation number. For DAN, the calculation of standard deviation is meaningless because of a naturally wide range of variation spanning one order of magnitude.

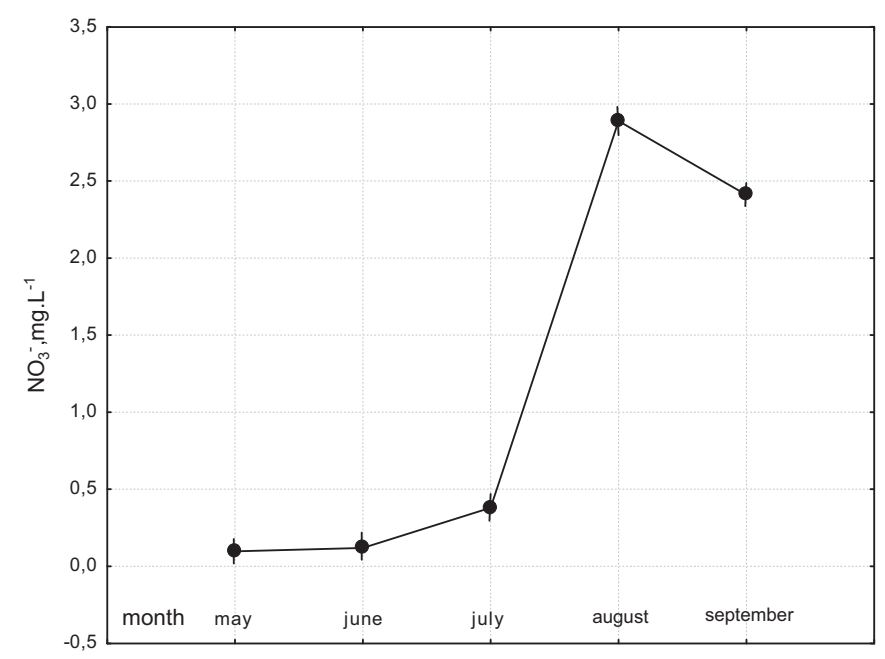

Fig. 3. Nitrate anion levels in water for the littoral zone of Lake Hupujarvi during the vegetation season of 2016. The diagram shows average monthly values; the variation range is indicated by the line passing through the point corresponding to the observation month.

The water level and the coefficient of external water exchange were consistently positively correlated $(r=0.68$, $p=0.03$ ). Both these parameters (especially the water exchange coefficient) showed a strong association with total precipitation $(r=0.66, p=0.04 ; r=0.86, p=0.002$; for the water level and $K_{\mathrm{W}}$, respectively). The correlation between hydrological variables and air temperature was not confirmed $(r=0.42, p=0.23 ; r=0.51, p=0.14)$.

\subsection{Variation in production variables and nitrate content}

In general, the chlorophyll $a$ content in the littoral water of Lake Hupujarvi varied within limits typical for the mesotrophic status of the water body (Tab. 1). The PP values also generally characterise the lake as mesotrophic. The DAN values varied within limits, which were generally typical for the lakes of the temperate zone. There was a clear indication of the well-known pattern of increasing photosynthetic activity (DAN) with decreasing chlorophyll $a$ levels $(r=-0.92$, $p=0.03$ ). The ratio of carotenoids and chlorophyll fluctuated around 1, with one or the other group of pigments becoming dominant at different observation dates. The nitrate concentration showed the following pattern (Fig. 3): from the very beginning of the season to August, the concentration remained relatively low, but during August and September, it rose rapidly by almost an order of magnitude, and then kept fluctuating at this level. This period of increased concentration coincided with an abundant growth of filamentous algae at the water surface. During the preceding years (2012, 2014-2015; Rizhinashvili, 2017), our measurements of nitrate concentration in the water of this lake have never showed values as high as in 2016 (not higher than $1.11 \mathrm{mg} \cdot \mathrm{L}^{-1}$ in the previous years versus $2.90 \mathrm{mg} \cdot \mathrm{L}^{-1}$ in 2016).

The nitrate content in rainwater was at trace levels throughout the vegetation season (less than $0.05 \mathrm{mg} \cdot \mathrm{L}^{-1}$ ).

\subsection{Relationships between production characteristics of phytoplankton, nitrate content and hydrological and meteorological conditions}

The concentrations of both types of phytoplankton pigments (chlorophyll $a$ and carotenoids) in water were significantly correlated $(r=0.91, p=0.0041)$. The concentration of chlorophyll $a$ did not show any significant and consistent correlation with the nitrate levels $(r=-0.48$, $p=0.28)$. In contrast, the concentration of carotenoids displayed a statistically significant trend of decreasing concentration with increasing nitrate content $(r=-0.77$, $p=0.04)$. On the other hand, the relationship of primary production and DAN with nitrate was not proven $(r=-0.06$, $p=0.93 ; r=0.58, p=0.30$, respectively).

The analysis of the system of paired associations with the hydrological and meteorological variables included in the analysis revealed the two groups of closely related variables (Fig. 4A,B). There is a relationship between pigments and air temperature (which was slightly stronger for chlorophyll than for carotenoids). Water level, water exchange coefficient and total precipitation are grouped together, with an especially close association between precipitation and water exchange (Fig. 4B). Our correlation graph showed that pigment levels were affected by nitrate and temperature, with nitrate, as already demonstrated, having an effect on carotenoids, while chlorophyll being clearly associated with temperature.

The factor analysis provides a method to determine the direction of variation in variables (Fig. 5). There is evidence of three directions of variation, because the first three factors collectively account for $96 \%$ of the total variance. In the 
Table 2. Assessment of variables $\left(\mathrm{NO}_{3}{ }^{-}\right.$concentration, water level $l$, water exchange coefficient $K_{\mathrm{w}}$, air temperature $t$, precipitation $\left.f\right)$ and regression model quality using multiple linear prediction of phytoplankton pigment content (chlorophyll $a$ and carotenoids) (forward stepwise algorithm).

\begin{tabular}{|c|c|c|c|c|c|c|c|c|c|c|c|c|}
\hline \multirow[t]{2}{*}{$\begin{array}{l}\text { Dependent } \\
\text { variable }\end{array}$} & \multirow[t]{2}{*}{$F(p)$} & \multirow[t]{2}{*}{$R\left(R^{2}\right)$} & \multicolumn{5}{|c|}{$\begin{array}{c}\text { Step } 1- \\
\mathrm{F}(p) \text { for independent variables }\end{array}$} & \multicolumn{5}{|c|}{$\begin{array}{c}\text { Step } 2- \\
F(p) \text { for independent variables }\end{array}$} \\
\hline & & & $\mathrm{NO}_{3}{ }^{-}$ & $l$ & $K_{\mathrm{w}}$ & $t$ & $f$ & $\mathrm{NO}_{3}^{-}$ & $l$ & $K_{\mathrm{w}}$ & $t$ & $f$ \\
\hline$a$ & $6.37(0.05)$ & $\begin{array}{l}0.75 \\
(0.56)\end{array}$ & $\begin{array}{l}1.46 \\
(0.28)\end{array}$ & $\begin{array}{l}0.48 \\
(0.52)\end{array}$ & $\begin{array}{l}0.32 \\
(0.60)\end{array}$ & $\begin{array}{l}6.37 \\
(0.05)\end{array}$ & $\begin{array}{l}1.48 \\
(0.28)\end{array}$ & $\begin{array}{l}1.27 \\
(0.32)\end{array}$ & $\begin{array}{l}0.06 \\
(0.82)\end{array}$ & $\begin{array}{l}0.07 \\
(0.80)\end{array}$ & + & $\begin{array}{l}2.22 \\
(0.21)\end{array}$ \\
\hline$k$ & $7.49(0.04)$ & $\begin{array}{l}0.77 \\
(0.59)\end{array}$ & $\begin{array}{l}7.49 \\
(0.04)\end{array}$ & $\begin{array}{l}1.64 \\
(0.26)\end{array}$ & $\begin{array}{l}2.24 \\
(0.20)\end{array}$ & $\begin{array}{l}3.79 \\
(0.11)\end{array}$ & $\begin{array}{l}1.02 \\
(0.36)\end{array}$ & + & $\begin{array}{l}0.08 \\
(0.79)\end{array}$ & $\begin{array}{l}0.06 \\
(0.82)\end{array}$ & $\begin{array}{l}6.99 \\
(0.06)\end{array}$ & $\begin{array}{l}3.34 \\
(0.14)\end{array}$ \\
\hline
\end{tabular}

F: Fisher's test; $p$ : confidence probability; $R$ : multiple correlation coefficient; " + " indicates the variables that were included in the model in the previous step; $F$ and $p$ values for the variables included in the current step are indicated in bold.

A

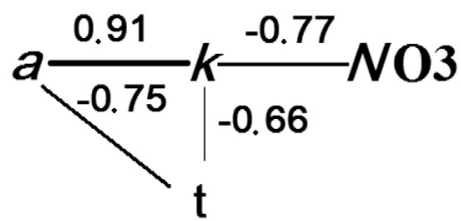

B

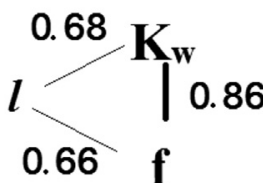

Fig. 4. Graph showing paired connections for pigment content (a: chlorophyll $a, \mathrm{k}$ : carotenoids), nitrate concentration and abiotic variables ( $t$ : air temperature; $l$ : water level; $f$ : total precipitation; $K_{\mathrm{w}}$ : water exchange coefficient). (A): system of connections for pigment content; (B): system of connections for precipitation levels and hydrological variables. Line thickness indicates connection strength. The graph was plotted using only those connections that have statistically significant Pearson's correlation coefficients of more than 0.60 (shown above the lines).

three-dimensional space of the first PCs, the concentrations of pigments and nitrate formed a separate group. Meteorological and hydrological parameters were clustered in a less compact group, with temperature showing some separation from the other parameters. In the first PC, all variables demonstrated a very tight association but to various degrees. Only one pattern was clearly present: the pigment levels and abiotic variables had an inverse association. The second PC can be tentatively termed the "nitrate" component: nitrates showed here a relationship with the precipitation level. The third PC cannot be adequately interpreted, because the loadings of all variables on this component were very low (it was generally lower than 0.50 ). The major amount of variance of pigment concentrations is thus caused by the variability of almost the entire set of the abiotic variables studied, including nitrate levels. At the same time, it can be suggested that precipitation accounts for at least $50 \%$ of the nitrate content.

During the first phase (step) of building a response model for chlorophyll $a$ (Tab. 2), air temperature was included in the model; during the second phase, no other variable was

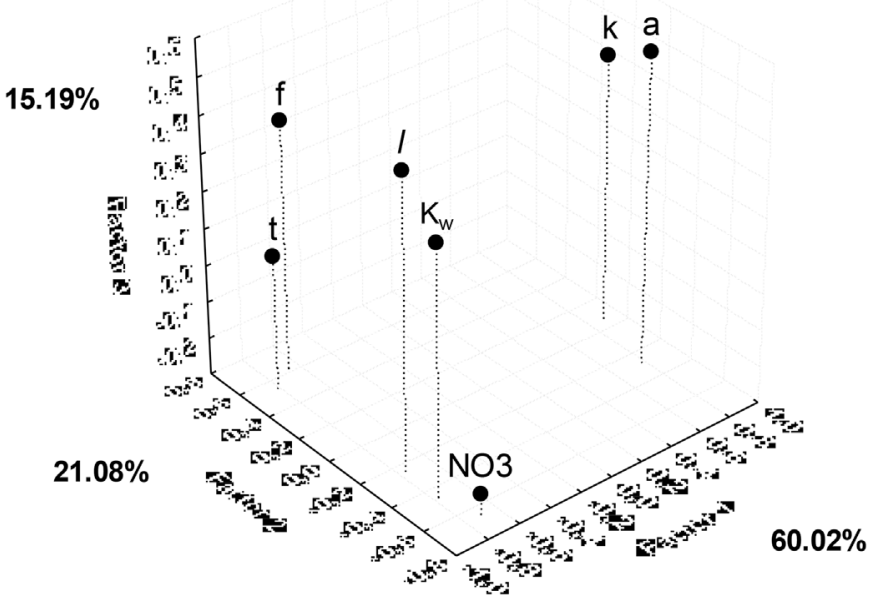

Fig. 5. Factor (component) structure of variables. The amount of variance explained by each factor is shown. See Figure 4 for abbreviations.

included. The results of stepwise approximation for the carotenoid model clearly showed that the nitrate concentration was the best predictor of carotenoid levels. Although air temperature was not included in the model, during the second step, it had a confidence level approaching the value of 0.05 , which was the threshold value for inclusion. Nevertheless, in this case, the hydrological parameters and total precipitation were also rejected. Judging from the final values of Fisher's test, the resulting approximation models were statistically significant.

The calculation of nitrate-nitrogen availability for the primary production averaged over the vegetation season showed that under the low nitrate concentrations observed during the first half of the season $\left(0.25 \mathrm{mg} \cdot \mathrm{L}^{-1}\right.$ on average $)$, the ratio of $\mathrm{PP}$ and $\mathrm{PP}_{\mathrm{NO} 3}$ was 1.54 . The value of "nitrate" production was $1.11 \mathrm{mgO}_{2} \cdot \mathrm{L}^{-1}$. This was essentially comparable with the maximum values of PP during the season. During the second half of the season, this ratio was 13.54 (the average nitrate concentration was $2.19 \mathrm{mg} \cdot \mathrm{L}^{-1}$ ). This implies that small nitrate concentrations at the beginning 


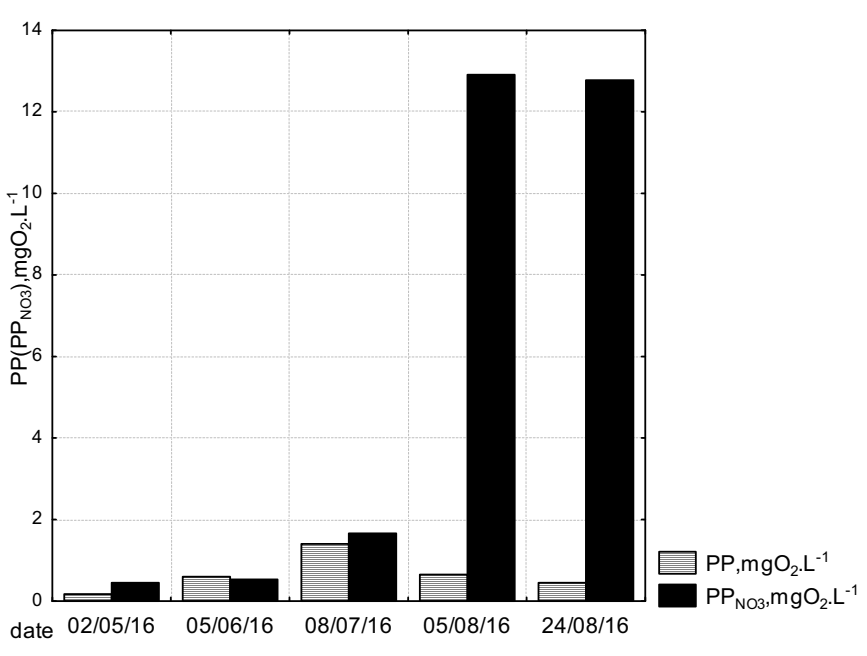

Fig. 6. Comparison between the measured values of primary production (PP) and nominal values of primary production calculated from the nitrate content using Redfield stoichiometry $\left(\mathrm{PP}_{\mathrm{NO} 3}\right)$. Examples of individual observations are shown.

of the season can limit production, while during the second half of the season, no limitation was present. Figure 6 provides a comparison between the measured PP and the nominal value $\mathrm{PP}_{\mathrm{NO} 3}$ (shown by individual examples of observations). It is clear that these two values are similar if the nitrate concentration is low. According to the stoichiometric analysis, the maximum observed intensity of production $(1.39 \mathrm{mg}$ $\mathrm{O}_{2} \cdot \mathrm{L}^{-1}$ ) can be maintained if the concentration of $\mathrm{NO}_{3}{ }^{-}$in water is $0.31 \mathrm{mg} \cdot \mathrm{L}^{-1}$, which is very close to the concentration that was actually observed during the first half of the season.

\section{Discussion}

Nitrate concentration demonstrates a strong correlation with the content of one of the pigment groups, carotenoids, but not with chlorophyll $a$. This correlation is high enough to create a predictive model by specifically selecting the nitrate concentration among all proposed variables (Tab. 2). The fundamental difference between the physiological roles of these two pigments is well known: chlorophyll participates in the production process, while carotenoids have only a supplementary protective function (Schluter et al., 1997). Chlorophyll is thus a metabolically active component of phytoplankton, while carotenoids are apparently associated with the total level of its biomass. Our correlation analysis indeed supports the view that carotenoids are components of the photosynthetic cells directly associated with the production process, rather than with the detritus. The ratio of these pigments can be an indicator of biogenic (in particular, nitrogen) limitation of planktonic algae (Manny, 1969; Schluter et al., 1997): when photosynthesis is limited, a relative amount of carotenoids in the pigment complex is increased. This also explains reduction in carotenoid levels with an increase in nitrate concentration. The correlation of chlorophyll $a$ and production variables with nitrates has not been proved in our study. In general, the relationship between biogenic elements (in particular, nitrogen compounds) and chlorophyll is fairly equivocal: some water bodies exhibit a clear correlation (Hennemann and Petrucio, 2016), while others show only an uncertain correlation or no correlation at all (Wu et al., 2014). At the same time, chlorophyll $a$ is significantly correlated with air temperature, which is consistent with observations by other authors (Luzar, 2009; Hennemann and Petrucio, 2016; Mineeva et al., 2016). Moreover, of all the variables used in our analysis, temperature is the best predictor for the concentration of this pigment (Tab. 2). This conclusion is clear evidence that metabolic processes, like any chemical reactions, are primarily dependent on temperature. Although to a lesser extent, carotenoids also exhibit correlation with this meteorological variable, which, in our opinion, lends support to the overall dependence of phytoplankton abundance in the water body on temperature.

Another aspect of a possible impact of nitrate on the production characteristics that we analysed is associated with the calculation of the nominal nitrate availability for PP. In a number of instances (during the first half of the season), the measured production values are in good agreement with the values calculated "from nitrate" (Fig. 6). This indicates that the production level and nitrate concentrations are in stoichiometric equilibrium, which provides indirect evidence of a possible support of production by this ion.

It is important that we study lake in the region where in phytoplankton composition diatoms usually predominant. These algae are the only taxon that uptake the nitrate as a source of nitrogen unlike other groups which prefer the ammonium (Glibert et al., 2016). So, in such conditions possible nitrate regulation of the productive processes receives causal explanation.

During the second half of the season, nitrogen was excessively available for production, which has driven the autotrophs towards peculiar group of the macrophytes (filamentous algae). The trophic status of our water body remains mesotrophic throughout the vegetation season, despite the transformations occurring among the producers. Filamentous algae is known to grow abundantly in water under excessive nitrogen load (Moss et al., 2013) and especially when the load is close to the critical level (Datsenko, 2007). The excessive nitrogen load at the second half of the season can be explained by unusual precipitation regime. The total precipitation was above normal level during the summer (Fig. 1). Our results show that the higher the total precipitation, the more intensive the water exchange in the lake. As a result, the lake becomes more dependent on the catchment. This dependence is apparently reflected in intensive leaching of substances from the catchment. This may explain a rapid rise of nitrate concentration in the water body (simultaneously with increasing precipitation) at the beginning of August, which has reached the values that had never been reported for Hupujarvi (Fig. 3). Our factor analysis demonstrates that the content of $\mathrm{NO}_{3}{ }^{-}$does show a noticeable correlation with the precipitation level (Fig. 5). It is important to note that rainwater contained only "traces" of this anion. As mentioned earlier, the nitrogen input into a water body is thought to be associated with the

\footnotetext{
${ }^{1}$ The influence of silica can be excluded because in our region the concentration of this element is high and lakes usually are not Silimited (Gashkina, 2011).
} 
precipitation level during the observation period (Moss et al., 2013). However, it is possible that the interaction mechanism between nitrate and hydrological conditions is more complex (Howden and Burt, 2009; Hayes et al., 2015). This assumption arises from a somewhat indistinct pattern of relationships that we observed between nitrate and hydrological variables. This aspect needs further study. At the same time, it is relevant for the purposes of the present study that the nitrate content occupies a separate position in the factor structure compared to the other variables (Fig. 5). Our preliminary conclusions on the nitrate regime are crucial for subsequent development of the problem of nitrate-nitrogen limitation in small lakes: it is necessary to take into consideration the hydrological conditions.

\section{Conclusions}

One of the groups of photosynthetic pigments, carotenoids, exhibits a well-established relationship with the level of nitrate anion in the water. This relationship presents itself in such a way that it can be potentially used for prognostic analyses. The concentration of chlorophyll $a$ does not show this kind of relationship. In a number of instances, the nitrate levels correspond to the level of primary production in terms of the stoichiometric ratio, which suggests that primary production is limited by nitrate-nitrogen. If the production potential manifested by a certain level of nitrate is not realised by phytoplankton, it can be used by filamentous algae.

All of the above implies that the ecosystem of a small shallow lake can be limited by nitrogen (or, given the trace content of the phosphate, may be co-limited by nitrogen and phosphorus).

The concentration of nitrogen in water is probably associated with the level of precipitation. Nitrate does not appear to be supplied by precipitation, but is rather leached by rains from the surface of the catchment. These conclusions, however, are preliminary and need further study.

The conclusions drawn from the present study should be taken into consideration in studying biogenic limitation of the ecosystems of small shallow lakes. In practical terms, the results of the present study provide first steps towards prediction of one of the indicators of phytoplankton growth, the content of two main types of pigment (chlorophyll $a$ and carotenoids). It is important to emphasise that the "conservative" portion of the pigment complex represented by carotenoids has so far received a little attention from researchers.

The relationship between nitrate and production characteristics of the ecosystems of small lakes needs to be further studied during seasons with another meteorological characteristic (in particular, during dry and moderately wet seasons).

Acknowledgements. The work on the manuscript was divided between the authors as follows: Rizhinashvili did main part of works and manuscript preparation; Maksimova analysed the concentration of the pigments and took part in discussion of the results. We bring our sincere gratitude to Natalia M. Selyanskaya (Russian State Hydrological Institute, St. Petersburg) for offering meteorological data.

\section{References}

Datsenko YuS. 2007. Evtrofirovanie vodokhranilishch (gidrologogidrokhimicheskie aspekty), GEOS, Moscow, 215 p.

Doganovsky AM. 2012. Gidrologiya sushi (obshchii kurs), RGGMU, St. Petersburg, 524 p.

Dolman AM, Mischke U, Wiedner C. 2016. Lake-type-specific seasonal patterns of nutrient limitation in German lakes, with target nitrogen and phosphorus concentrations for good ecological status. Freshw Biol 61: 444-456.

Freese HM, Gors S, Karsten U, Schumann R. 2007. Dissolved inorganic nutrients and organic substrates in the River Warnow (North-Eastern Germany)-utilisation by bacterioplankton. Limnologica 37: 264-277.

Gashkina NA. 2011. Zonal features of the distribution of biogenic elements and organic matter in small lakes. Water Resour 38: 352-371.

Glibert PM, Wilkerson FP, Dugdale RC, Raven JA, Dupont CL, Leavitt PR, Parker AE, Burkholder JM, Kana TM. 2016. Pluses and minuses of ammonium and nitrate uptake and assimilation by phytoplankton and implications for productivity and community composition, with emphasis on nitrogen-enriched conditions. Limnol Oceanogr 61: 165-197.

Håkanson L, Boulion VV. 2003. A general dynamic model to predict biomass and production of phytoplankton in lakes. Ecol Model 165: 285-301.

Hayes NM, Vanni MJ, Horgan MJ, Renwick WH. 2015. Climate and land use interactively affect lake phytoplankton nutrient limitation status. Ecology 96: 392-402.

Hennemann MC, Petrucio MM. 2016. High chlorophyll a concentration in a low nutrient context: discussions in a subtropical lake dominated by Cyanobacteria. J Limnol 75: 520-530.

Howden NJK, Burt TP. 2009. Statistical analysis of nitrate concentrations from the rivers Frome and Piddle (Dorset, UK) for the period 1965-2007. Ecohydrology 2: 55-65.

Johnson KS. 2010. Simultaneous measurements of nitrate, oxygen, and carbon dioxide on oceanographic moorings: observing the Redfield ratio in real time. Limnol Oceanogr 55: 615-627.

Lean DRS. 1973. Phosphorus dynamics in lake water. Science 179: 678-680.

Lepisto L. 1999. Phytoplankton Assemblages Reflecting the Ecological Status of Lakes in Finland, Finnish Environment Institute, Helsinki, 45 p.

Likens GE. 1975. Primary production of inland aquatic ecosystems. In: Primary productivity of the biosphere, Springer-Verlag, Berlin, Heidelberg, New York, pp. 151-165.

Lozovik PA, Borodulina GS. 2009. Nitrogen compounds in the surface and subsurface waters of Karelia. Water Resour 36: 672-682.

Luzar T. 2009. Dynamics and possibility of prediction of chlorophyll $a$ concentration in a selected Oder river profile. Casopis Slezského Zemského Muzea (A) 58: 27-38.

Manny BA. 1969. The relationship between organic nitrogen and the carotenoid to chlorophyll $a$ ratio in five freshwater phytoplankton species. Limnol Oceanogr 14: 69-79.

Mineeva NM, Korneva LG, Solovyova VV. 2016. Photosynthetic activity of the phytoplankton in the reservoirs of the Volga river. Inland Water Biol 9: 116-125.

Moss B, Jeppesen E, Sondergaard M, Lauridsen TL, Liu Z. 2013. Nitrogen, macrophytes, shallow lakes and nutrient limitation: resolution of a current controversy? Hydrobiologia 710: 3-21.

Nesvetova GI. 2002. Gidrokhimicheskie usloviya funktsionirovaniya ekosistemy Barentseva morya, PINRO, Murmansk, 295 p. 
Parsons TR, Strickland JDH. 1963. Discussion of spectrophotometric determination of marine-plant pigments with revised equations for ascertaining chlorophylls and carotenoids. J Mar Res 21: $155-163$.

Quiros R. 2003. The relationship between nitrate and ammonia concentrations in the pelagic zone of lakes. Limnetica 22: $37-50$.

Report of SCOR-UNESCO Working Group 17 on Determination of Photosynthetic Pigments (June 4-6, 1964), 1964, UNESCO, Paris, $12 \mathrm{p}$.

Rizhinashvili AL. 2017. Small and shallow previously unstudied lakes: land-use, overgrowth and eutrophication. Manag Environ Qual Int J 28: 120-136.

Rizhinashvili AL, Maksimova OB. 2018. Evaluation of primary production provision in small lake and its trophic state. Hydrobiol $J$ 54: $31-42$.
Schluter L, Riemann B, Sondergaard M. 1997. Nutrient limitation in relation to phytoplankton carotenoid/chlorophyll $a$ ratios in freshwater mesocosms. J Plankton Res 19: 891-906.

Trifonova I, Denisova I, Stanislavskaia E, Aphanasieva A, Ulianova D. 2002. The relative contributions by phytoplankton and macrophytes to primary production of two shallow lakes (Karelian Isthmus, Russia). Pol J Ecol 50: 357-370.

Vanni MJ, Renwick WH, Bowling AM, Horgan MJ, Christian AD. 2010. Nutrient stoichiometry of linked catchment-lake systems along a gradient of land-use. Freshw Biol 56: 791-811.

Williams JJ, Beutel M, Nurse A, Moor B, Hampton SE, Saros JE. 2016. Phytoplankton responses to nitrogen enrichment in Pacific Northwest, USA Mountain Lakes. Hydrobiologia 776: 261-276.

Wu Z, Lai X, Zhang L, Cai Y, Chen Y. 2014. Phytoplankton chlorophyll $a$ in Lake Poyang and its tributaries during dry, mid-dry and wet seasons: a 4-year study. Knowl Manag Aquat Ecosyst 412: 14.

Cite this article as: Rizhinashvili AL, Maksimova OB. 2018. Is nitrate a driver for pigments of phytoplankton (a case study from a small shallow European lake)? Ann. Limnol. - Int. J. Lim. 54: 38 